\title{
CHAF1B promotes proliferation and reduces apoptosis in 95-D lung cancer cells and predicts a poor prognosis in non-small cell lung cancer
}

\author{
YAN DUAN ${ }^{1-3}$, TANZHEN LIU $^{3}$, SHENGWEN LI $^{4}$, MINGGUANG HUANG ${ }^{2}$, \\ XIAOYU LI ${ }^{2}$, HUI ZHAO ${ }^{3}$ and JIANQIANG $\mathrm{LI}^{3}$ \\ ${ }^{1}$ Department of Internal Medicine, Shanxi Medical University, Taiyuan, Shanxi 030001; \\ ${ }^{2}$ Intensive Care Unit, Shanxi Provincial Cancer Hospital, The Affiliated Tumor Hospital of Shanxi Medical University, \\ Taiyuan, Shanxi 030013; ${ }^{3}$ Department of Respiratory and Critical Medicine, The Second Affiliated Hospital of \\ Shanxi Medical University, Taiyuan, Shanxi 030001; ${ }^{4}$ Department of Respiratory and Critical Medicine, \\ Shanxi Provincial People's Hospital Affiliated to Shanxi Medical University, \\ Taiyuan, Shanxi 030012, P.R. China
}

Received August 1, 2018; Accepted January 18, 2019

DOI: $10.3892 /$ or.2019.6994

\begin{abstract}
Chromatin assembly factor 1 subunit B (CHAF1B) participates in DNA synthesis and repair. High $\mathrm{CHAF} 1 \mathrm{~B}$ expression has been associated with a poor prognosis in several types of cancers. However, no study has evaluated the clinical significance and biological function of CHAF1B in non-small cell lung cancer (NSCLC). In the present study, we aimed to investigate $\mathrm{CHAF} 1 \mathrm{~B}$ expression and its role in NSCLC. In the present study, it was revealed that CHAF1B was highly expressed in NSCLC lung tissues and 95-D cells. Kaplan-Meier survival analysis indicated that high CHAF1B expression in tumour tissue was associated with poor clinical outcomes in NSCLC patients. Multivariate Cox analyses revealed that lymph node metastasis, tumour-node-metastasis (TNM) stage and CHAF1B expression were independent prognostic factors in NSCLC patients. Moreover, CHAF1B knockdown in 95-D cells markedly inhibited tumour proliferation, reduced colony formation, induced cell cycle arrest and promoted apoptosis. In vivo studies demonstrated that CHAF1B knockdown inhibited the growth of transplanted tumours. Furthermore, our results revealed that the mechanism by which CHAF1B induced apoptosis was mediated by the activation of the p53-dependent apoptotic signalling pathway (BAK/Bcl-2/caspase-3) in 95-D cells. These data indicated
\end{abstract}

Correspondence to: Professor Jianqiang Li or Professor Hui Zhao, Department of Respiratory and Critical Medicine, The Second Affiliated Hospital of Shanxi Medical University, 382 Wuyi Road, Taiyuan, Shanxi 030001, P.R. China

E-mail: ljqhx@sina.com

E-mail: hui_zhao@sxmu.edu.cn

Key words: chromatin assembly factor 1 subunit B, non-small cell lung cancer, proliferation, p53-dependent apoptosis pathway that CHAF1B plays an important role in tumourigenesis and may be a therapeutic molecular target to counter NSCLC progression.

\section{Introduction}

Lung cancer is one of the most prevalent malignancies and a major public health issue worldwide. In 2017, the estimated number of cancer cases in the US was $1,688,780$, of which $13 \%$ were lung cancer. In addition to being the most common cancer, lung cancer is a highly fatal disease, accounting for $26 \%$ of all cancer-related deaths (1). In China, lung cancer is not only the most common cancer, but also the leading cause of cancer-related deaths (2). In recent years, with the rapid development of high-throughput sequencing technologies, targeted therapy has emerged as a treatment for non-small cell lung cancer (NSCLC), the most frequent histological type of lung cancer, in addition to surgical resection, radiotherapy and chemotherapy (3). However, only a small proportion of NSCLC patients benefit from treatment. The 5-year relative survival rate of lung cancer patients is still only $18 \%$ (1). The heterogeneity of NSCLC is a major challenge (4). Therefore, the discovery of new functional genes and the identification of novel therapeutic targets are urgently needed to combat heterogeneity and to optimize individualized treatment strategies.

Chromatin assembly factor 1 (CAF-1) is a 3-subunit protein complex comprised of p150, p60 and p48 subunits, along with the newly synthesized histone $\mathrm{H} 3$ and acetylated $\mathrm{H} 4$ dimer, that promotes DNA replication and the subsequent assembly of nucleosomes $(5,6)$. Chromatin assembly factor 1 subunit B (CHAF1B), the p60 subunit of CAF-1, plays an important role in DNA replication and chromatin assembly in proliferating tissues (7). Tumour cells are generally characterized by a high rate of proliferation (8). Therefore, CHAF1B is speculated to play an essential role in the pathogenesis of malignant tumours. Studies have revealed that CHAF1B 
overexpression is significantly associated with poor outcomes and that $\mathrm{CHAF} 1 \mathrm{~B}$ has potential in predicting the prognosis in various types of cancers, including high-grade gliomas, prostate, tongue and breast cancer, salivary gland tumours, renal carcinoma, endometrial and cervical cancer, and melanoma (9-16). However, no study has evaluated the expression or the clinical value of CHAF1B in NSCLC or conducted functional investigations. Therefore, in the present study we aimed to investigate the association of CHAF1B expression with clinicopathological features and prognosis and its function in NSCLC. Furthermore, the effects and mechanism of CHAF1B on NSCLC cell proliferation in vitro and in vivo were examined. The present study is exploratory; our findings provide important insights into the role of $\mathrm{CHAF} 1 \mathrm{~B}$ and the potential implications for NSCLC therapy.

\section{Materials and methods}

Patients and clinical samples. Archived formalin-fixed paraffin-embedded tumour tissues from 135 NSCLC patients who had undergone surgical resection between January 2010 and June 2011 were evaluated. The last follow-up was completed on July 1, 2016. The median follow-up duration was 62.47 months. This group of samples was used for immunohistochemical examination. The other group of NSCLC cases included 27 patients whose cancer and paired non-neoplastic tissues were removed and immediately frozen after surgery for quantitative real-time polymerase chain reaction (qRT-PCR) analyses. These patients underwent surgery from April 2016 to July 2016. All patients were from Shanxi Provincial Cancer Hospital (Shanxi, China); their clinical information was obtained from an electronic medical record system, and follow-up information was obtained by telephone interviews. The aspects of the present study involving human participants were approved by the Ethics Committee of Shanxi Provincial Cancer Hospital, and the study was conducted in accordance with the Declaration of Helsinki. All patients provided written informed consent.

Immunohistochemistry (IHC). Formalin-fixed paraffinembedded tissues were sectioned at $4-\mu \mathrm{m}$ thickness and mounted on slides to detect the protein expression of CHAF1B and Ki-67 using the Ventana Bench Mark XT Automated Stainer (Ventana Medical Systems, Inc., Tucson, AZ, USA). Anti-p60 CAF1 (dilution 1:500; EPR6105; cat. no. ab109442; Abcam, Cambridge, MA, USA) and anti-Ki67 (dilution 1:200; ab16667; Abcam) antibodies were applied to the slides. Negative control slides were stained without the primary antibody. Slides were scanned for evaluation using Leica Microsystems (Leica Microsystems GmbH, Wetzlar, Germany). Semi-quantitative scoring was represented by staining intensity multiplied by the percentage of positive cells. The staining intensity was graded as none (0), weak (1), moderate (2), or strong (3) staining. The percentage of positive cells was scored as 0 (none), 1 (1-25\%), $2(26-50 \%), 3(51-75 \%)$, or $4(76-100 \%)$. The sections were independently scored by 2 experienced pathologists. The observer selected 6 fields of view randomly under an x40 light microscope for assessment and then the average was used as the final score. The total score ranged from 0 to 12 and was used to classify the expression as high or low.
Table I. Primer sequences for qRT-PCR.

Primer

name

Sequence

\begin{tabular}{ll} 
CHAF1B & F: 5'-CGGACACTCCACCAAGTTCT-3' \\
& R: 5'-CCAGGCGTCTCTGACTGAAT-3' \\
Caspase-3 & F: 5'-AACTGGACTGTGGCATTGAG-3' \\
& R: 5'-ACAAAGCGACTGGATGAACC-3' \\
p53 & F: 5'-TTATGGCGGGAGGTAGACTG-3' \\
& R: 5'-GTTCCGAGAGCTGAATGAGG-3' \\
BAK & F: 5'-TACCTCCACCAGCAGGAAC-3' \\
& R: 5'-GGTAGACGTACAGGGCCAG-3' \\
Bcl-2 & F: 5'-CGACGACTTCTCCCGCCGCTACCGC-3' \\
& R: 5'-CCGCATGCTGGGGCCGTACAGTTCC-3' \\
$\beta$-actin & F: 5'-CCAGGCGTCTCTGACTGAAT-3' \\
& R: 5'-CCAGGCGTCTCTGACTGAAT-3' \\
\hline
\end{tabular}

qRT-PCR, for quantitative real-time polymerase chain reaction; CHAF1B, chromatin assembly factor 1 subunit $\mathrm{B}$; F, forward; $\mathrm{R}$, reverse.

Quantitative real-time polymerase chain reaction ( $q R T-P C R)$. Total RNA was extracted using TRIzol (Invitrogen; Thermo Fisher Scientific, Inc., Waltham, MA, USA) following the manufacturer's instructions. cDNA was synthesized from $1,000 \mathrm{ng}$ of total RNA using QuantScript RT kit (Tiangen Biotech Co., Ltd., Beijing, China). mRNA expression was detected using qRT-PCR on an Applied Biosystems 7500 Real-Time PCR System (Applied Biosystems, Foster City, CA, USA) using SYBR-Green I Master Mix (Tiangen Biotech Co., Ltd.). The thermocycling conditions were $15 \mathrm{~min}$ at $95^{\circ} \mathrm{C}$, followed by 40 cycles of $45 \mathrm{sec}$ at $95^{\circ} \mathrm{C}$ and $30 \mathrm{sec}$ at $60^{\circ} \mathrm{C}$. The system was set as $10 \mu \mathrm{l}$. Oligonucleotide primers were synthesized by Sangon Biotech Co., Ltd. (Shanghai, China) and the sequences are provided in Table I. The expression level of the gene of interest was normalized to the expression level of the internal control $\beta$-actin and calculated using the $2^{(-\Delta \Delta C T)}$ method (17).

Western blot analysis. Cells or fresh tissues were lysed with RIPA Lysis and Extraction Buffer (Life Technologies; Thermo Fisher Scientific, Inc.) supplemented with protease inhibitors (Roche Diagnostics, Indianapolis, IN, USA) and measured by BCA protein assay kit (cat. no. P0012S; Beyotime Institute of Biotechnology, Shanghai, China). Protein samples were separated by $8 \%$ sodium dodecyl sulfate-polyacrylamide gel electrophoresis (SDS-PAGE), and then transferred to polyvinylidene fluoride (PVDF) membranes. The membranes were blocked using non-fat powdered milk (cat. no. A600669; Sangon Biotech Co., Ltd., Shanghai, China) for $4 \mathrm{~h}$ at room temperature. Then, the membranes were incubated at $4{ }^{\circ} \mathrm{C}$ overnight with the following primary antibodies before incubation with horseradish peroxidase-labelled goat anti-rabbit IgG (dilution 1:2,000; cat. no. SA00001-2; Proteintech Group, Inc., Chicago, IL, USA) or goat anti-mouse 
Table II. Sequences of shRNAs.

shRNA

Sequence

Random shRNA

CHAF1B-HOMO-416

CHAF1B-HOMO-550

CHAF1B-HOMO-675
CACCGTTCTCCGAACGTGTCACGTTTCAAGAGAACGTGACACGTTCGGAGAATTTTTTG CACCGGAAGGTGAATGATAACAAGGTTCAAGAGACCTTGTTATCATTCACCTTCCTTTTTTG CACCGCAACTGATGGGAATTTAATGTTCAAGAGACATTAAATTCCCATCAGTTGCTTTTTTG CACCGGACCCTTTGGGTCAATATGTTTCAAGAGAACATATTGACCCAAAGGGTCCTTTTTTG

shRNA, short hairpin RNA; CHAF1B, chromatin assembly factor 1 subunit B.

IgG (dilution 1:2,000; cat. no. SA00001-1; Proteintech Group, Inc.) for $40 \mathrm{~min}$ at room temperature: Anti-p60 CAF1 (EPR6105; dilution 1:20,000; cat no. ab109442; Abcam), anti-p53 (PAb 240; dilution 1:1,000; cat. no. ab26; Abcam), anti-BAK (Y164; dilution 1:1,000; cat. no. ab32371; Abcam), anti-Bcl-2 (E17; dilution 1:1,000; cat. no. ab32124; Abcam) and anti-caspase-3 (31A1067, dilution 1:1,000; cat. no. ab13585; Abcam). Finally, the proteins were visualized by chemiluminescence and autoradiography with Super ECL Plus (P1010; Applygen Technologies, Inc., Beijing, China). The protein contents were normalized to the level of GAPDH. All experiments were repeated 3 times.

Cell culture and transfection. The normal human bronchial epithelial (HBE) cell line and lung cancer cell lines A549, 95-D and NCI-H292 were purchased from the Cell Bank of the Chinese Academy of Sciences (Shanghai, China). Cells were maintained in RPMI-1640 medium (HyClone; GE Healthcare Life Sciences, Logan, UT, USA) supplemented with $10 \%$ fetal bovine serum (FBS; Gibco; Thermo Fisher Scientific, Inc.) and $100 \mu \mathrm{g} / \mathrm{ml}$ penicillin/streptomycin. All cells were cultured in a humidified incubator at $37^{\circ} \mathrm{C}$ with $5 \% \mathrm{CO}_{2}$. Cells were transfected using Lipofectamine 2000 reagent (Invitrogen; Thermo Fisher Scientific, Inc.) according to the manufacturer's instructions. Briefly, 1 day prior to transfection, 2,500 95-D cells/well were plated in 6-well plates in $1 \mathrm{ml}$ of growth medium without antibiotics for in vitro transfection. To evaluate the gene silencing efficiency, we analysed 4 different CHAF1B shRNA (short hairpin RNA) (sh-CHAF1B) sequences (Shanghai GenePharma Co., Ltd., Shanghai, China) (Table II). The non-targeting shRNA (sh-NC) used as a negative control had a scrambled sequence. For stable transfection, cells were selected with complete growth medium containing G418 (500 $\mu \mathrm{g} / \mathrm{ml})($ Gibco; Thermo Fisher Scientific, Inc.). Colonies of G418-resistant cells were pooled after 3 weeks, and CHAF1B-knockdown cells were detected by qRT-PCR and western blotting.

Cell proliferation assay. A CCK-8 assay was used to detect cell proliferation in vitro. Cells transfected with sh-NC or sh-CHAF1B were seeded in 96-well plates at a density of $1,000$ cells/well (100 $\mu \mathrm{l})$ and incubated for 24, 48, 72 and $96 \mathrm{~h}$ in an incubator. Then, $10 \mu \mathrm{l}$ of Cell Counting Kit- 8 reagent (CCK-8; Dojindo Molecular Technologies, Inc., Kumamoto, Japan) was added to each well and incubated for $3 \mathrm{~h}$. At the end of incubation, the absorbance (optical density; OD) was read at 450 and $630 \mathrm{~nm}$ wavelengths using a multi-well spectrophotometer (Thermo Fisher Scientific, Inc.).
Colony formation assay. Transfected cells were seeded in 6-well plates at a density of 2,000 cells/well and incubated with RPMI-1640 supplemented with 10\% FBS. Two weeks later, the cells were washed and fixed with $4 \%$ paraformaldehyde and stained with crystal violet. Colonies containing $>50$ cells were counted using a light microscope (Carl Zeiss Primo Vert; Carl Zeiss, Jena, Germany). The experiment was independently performed in triplicate.

Cell cycle analysis. Cells transfected with sh-CHAF1B or sh-NC were collected, washed with phosphate-buffered saline (PBS), and fixed with $75 \%$ ice-cold ethanol at $4^{\circ} \mathrm{C}$ overnight. Then, the fixed cells were incubated with PBS containing propidium iodide (PI; $10 \mu \mathrm{g} / \mathrm{ml})$ and RNase A $(0.5 \mathrm{mg} / \mathrm{ml})$ for $20 \mathrm{~min}$. DNA content analysis was performed by flow cytometry using a BD FACSCalibur instrument (BD Biosciences, Franklin Lakes, NJ, USA). The distribution of cells in different cell cycle phases was analysed with WinMDI software (Scripps Institute, La Jolla, CA, USA) on a FACSCalibur ${ }^{\mathrm{TM}}$ System (BD Biosciences).

Apoptosis assay. Apoptosis assays were performed by flow cytometry using an Annexin V-FITC Apoptosis Detection kit (Nanjing KeyGen Biotech Co., Ltd., Nanjing, China) according to the manufacturer's instructions. The labelled cells were analysed by flow cytometry using a BD FACSCalibur instrument (BD Biosciences).

In vivo studies. Twelve 4- to 6-week-old male BALB/c nude mice were purchased from the Experimental Laboratory Animal Center of Beijing University (Beijing, China). The animal studies were approved by the Shanxi Institute of Tumor Research, and all procedures were performed in accordance with the relevant guidelines and regulations. All mice were fed under specific pathogen-free (SPF) at $25 \mathrm{C}$ with $50 \%$ humidity. The mice were randomly divided into 2 groups of 6 for inoculation with 95-D cells with plasmids expressing sh-CHAF1B or sh-NC. Approximately $5 \times 10^{6}$ cells were suspended in $0.2 \mathrm{ml}$ of PBS and subcutaneously injected into the right flanks of mice. To monitor tumour growth, we measured the tumours every 5 days. Tumour volume (V) was determined by measuring the length (L) and width (W) with callipers and calculated using the following formula: $\mathrm{V}=\left(\mathrm{L} \mathrm{x} \mathrm{W}^{2}\right) \times 0.5(18)$. At the end of the study, the maximum tumour weight did not exceed $10 \%$ of the mouse weight. All mice were sacrificed by cervical dislocation after anesthesia. The tumours were dissected and weighed. Using qRT-PCR and IHC, we analysed CHAF1B expression in xenograft tumours. 


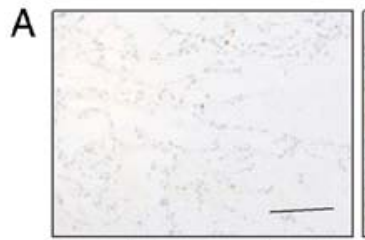

Normal alveolar epithelium

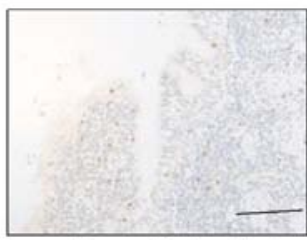

Normal bronchial epithelium

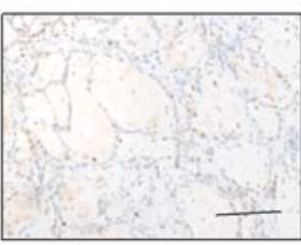

Adenocarcinoma low expression

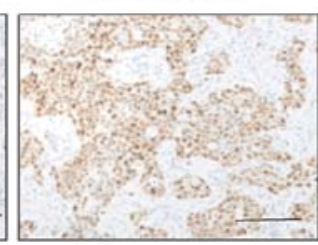

Adenocarcinoma high expression

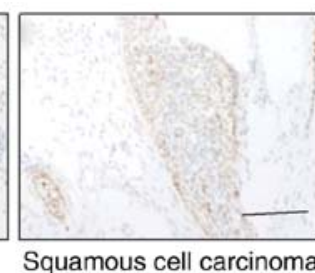
low expression

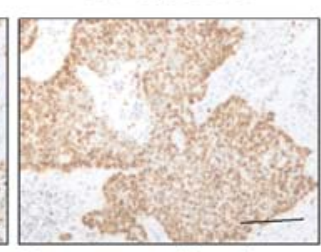

Squamous cell carcinoma high expression

B

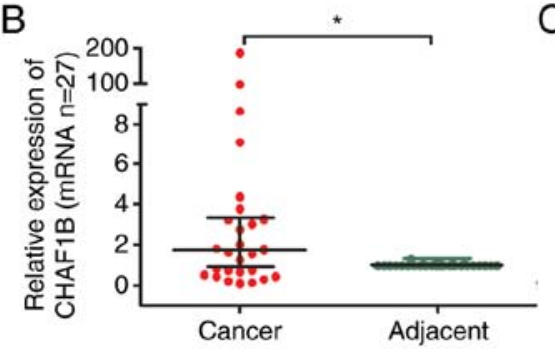

C
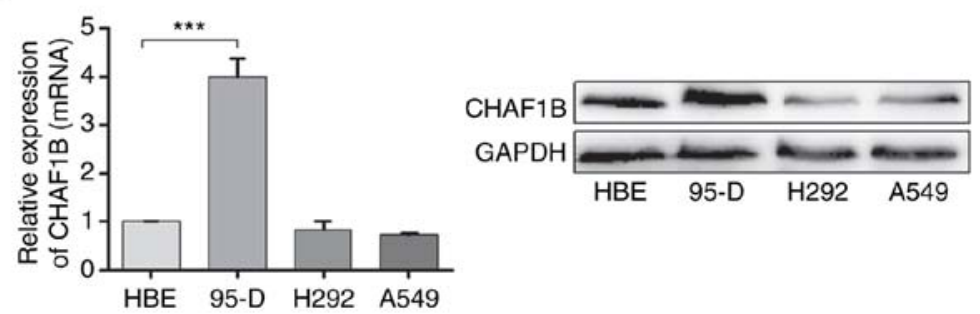

Figure 1. CHAF1B is highly expressed in NSCLC tissues and 95-D cells. (A) Immunohistochemical staining for CHAF1B, and IHC score analysis of CHAF1B expression in histologically distinct subtypes of NSCLC (scale bars, $100 \mu \mathrm{m}$ ). (B) The expression of CHAF1B mRNA was assessed by qRT-PCR in 27 NSCLC tumours and matched non-malignant tissues $(\mathrm{P}=0.0218)$. (C) The expression of CHAF1B mRNA was assessed by qRT-PCR in 3 NSCLC cell lines and normal HBE cells; $\beta$-actin was used as the normal control. Western blot analysis of CHAF1B protein levels in NSCLC cell lines and HBE cells. GAPDH was used as a loading control. Data are presented as the mean $\pm \mathrm{SD}$. ${ }^{*} \mathrm{P}<0.05 ;{ }^{* * *} \mathrm{P}<0.001$. CHAF1B, chromatin assembly factor 1 subunit $\mathrm{B}$; NSCLC, non-small cell lung cancer; IHC, immunohistochemistry; HBE, human bronchial epithelial; SD, standard deviation.

Statistical analyses. Statistical analysis was performed using SPSS software (version 13; SPSS, Inc., Chicago, IL, USA). The data are presented as the mean \pm standard deviation (SD) from at least 3 independent experiments. Differences were compared using parametric tests or 2 independent rank-sum tests. Potential statistical associations between CHAF1B and Ki-67 were estimated using Spearman's correlation analysis. The optimal immunohistochemical cut-off scores for CHAF1B were determined using time-dependent receiver operating characteristic (ROC) curve analysis. Univariate and multivariate analyses were performed with Cox proportional hazards regression models to identify possible factors that can influence patient survival. Kaplan-Meier survival curves were constructed. Overall survival (OS) was evaluated from the date of surgery to the date of death or the end of follow-up. Disease-free survival (DFS) was assessed from the date of surgery to the date of cancer recurrence and metastasis or the end of follow-up. $\mathrm{P}<0.05$ was considered to indicate a statistically significant difference.

\section{Results}

CHAF1B is overexpressed in NSCLC tissues and 95-D lung cancer cells. To determine CHAF1B expression in NSCLC, we analysed its protein and mRNA levels in human NSCLC tissues by IHC and qRT-PCR, respectively. First, CHAF1B protein was immunohistochemically stained in cancer and adjacent normal tissues from a cohort of 135 NSCLC patients.
CHAF1B immunoreactivity was observed in the nucleus of squamous cell carcinoma and adenocarcinoma tissues. However, CHAF1B was rarely expressed in paired adjacent healthy lung tissues. CHAF1B protein levels were significantly higher in cancer tissues than in non-tumour tissues from NSCLC patients (Fig. 1A). The mean IHC score was $5.04 \pm 0.23$ in tumour tissues and $0.69 \pm 0.07$ in adjacent normal tissues $(n=135, P<0.0001)$. To further validate this observation, we detected CHAF1B mRNA expression in another cohort of 27 NSCLC patients. Among these cases, CHAF1B mRNA levels were elevated in 16 tumour tissues relative to those in adjacent normal tissues (Fig. 1B). CHAF1B mRNA levels were 8.5-fold higher in tumour tissues than in adjacent normal tissues. Notably, CHAF1B mRNA expression displayed a 102- and 189-fold increase in squamous cell carcinoma samples. Furthermore, the expression of CHAF1B mRNA and protein in the lung cancer cell lines 95-D, NCI-H292, and A549 was examined. CHAF1B mRNA expression in 95-D lung cancer cells was $\sim 4$ times higher than that in normal $\mathrm{HBE}$ cells (Fig. 1C). Therefore, these data indicated that CHAF1B was overexpressed in human lung cancer tissues and 95-D lung cancer cells.

High CHAFIB expression in tumour tissues is associated with poor clinical outcomes in NSCLC patients. We divided patients into a high-expression and a low-expression group based on CHAF1B distribution using time-dependent ROC curve analysis. The immunohistochemical cut-off score for 
Table III. The relationship of CHAF1B expression with clinicopathological parameters in NSCLC patients.

\begin{tabular}{|c|c|c|c|c|c|c|}
\hline \multirow[b]{2}{*}{ Variables } & \multirow[b]{2}{*}{ Groups } & \multicolumn{2}{|c|}{ No. of patients } & \multirow[b]{2}{*}{$\chi^{2}$} & \multirow[b]{2}{*}{$\phi$} & \multirow[b]{2}{*}{ P-value } \\
\hline & & Low expression $(\mathrm{N})$ & High expression $(\mathrm{N})$ & & & \\
\hline \multirow[t]{2}{*}{ Sex } & Male & 47 & 55 & 7.102 & -0.229 & 0.008 \\
\hline & Female & 24 & 9 & & & \\
\hline \multirow[t]{2}{*}{ Pathological type } & Adenocarcinoma & 52 & 18 & 27.440 & 0.451 & $<0.001$ \\
\hline & Squamous & 19 & 46 & & & \\
\hline \multirow[t]{2}{*}{ Lymph node metastasis } & No & 48 & 34 & 2.960 & 0.148 & 0.085 \\
\hline & Yes & 23 & 30 & & & \\
\hline \multirow[t]{2}{*}{ Vascular invasion } & No & 63 & 58 & 0.130 & -0.031 & 0.719 \\
\hline & Yes & 8 & 6 & & & \\
\hline \multirow[t]{2}{*}{ Smoking } & No & 36 & 13 & 13.446 & 0.316 & $<0.001$ \\
\hline & Yes & 35 & 51 & & & \\
\hline \multirow{2}{*}{ Age (years) } & $<60$ & 46 & 37 & 0.692 & 0.072 & 0.406 \\
\hline & $\geq 60$ & 25 & 27 & & & \\
\hline \multirow[t]{2}{*}{ Histological grade } & III & 28 & 40 & 7.162 & -0.230 & 0.007 \\
\hline & $\mathrm{I} / \mathrm{II}$ & 43 & 24 & & & \\
\hline \multirow[t]{3}{*}{ TNM stage } & I & 32 & 14 & 12.643 & $0.306^{\mathrm{a}}$ & 0.002 \\
\hline & II & 29 & 26 & & & \\
\hline & III & 10 & 24 & & & \\
\hline \multirow[t]{3}{*}{ Tumour size $(\mathrm{cm})$} & $<3$ & 19 & 3 & 20.822 & $0.393^{\mathrm{a}}$ & $<0.001$ \\
\hline & $\geq 3,<5$ & 39 & 29 & & & \\
\hline & $\geq 5$ & 13 & 32 & & & \\
\hline
\end{tabular}

${ }^{a}$ Correlation coefficients represent Cramer V coefficients. CHAF1B, chromatin assembly factor 1 subunit B; NSCLC, non-small cell lung cancer; TNM stage, tumor-node-metastasis stage of lung cancer. $\phi$, correlation coefficient.

CHAF1B protein was 4.83 . To study the association between CHAF1B expression and clinicopathological parameters in patients with NSCLC, we evaluated the association between CHAF1B expression and clinicopathological variables and determined that $\mathrm{CHAF} 1 \mathrm{~B}$ protein expression was significantly correlated with sex $(\mathrm{P}=0.008)$; smoking status $(\mathrm{P}<0.001)$; pathological type $(\mathrm{P}<0.001)$; histological grade $(\mathrm{P}=0.007)$; TNM stage $(\mathrm{P}=0.002)$; and tumour size $(\mathrm{P}<0.001)$ (Table III). Notably, a high proportion of $\mathrm{CHAF} 1 \mathrm{~B}$ overexpression was observed in males, smokers and patients with squamous cell carcinoma. However, CHAF1B expression was not correlated with age, lymph node metastasis, or vascular invasion. To investigate patient survival, univariate and multivariate analyses were conducted. The results of the univariate analyses indicated that histological grade, lymph node metastasis, TNM stage, tumour size and $\mathrm{CHAF} 1 \mathrm{~B}$ expression were potential predictors of OS in this cohort of patients. High CHAF1B expression was associated with a higher risk of death $(\hat{\beta}=0.89)$. Multivariate analysis indicated that lymph node metastasis, TNM stage and CHAF1B expression were possible prognostic markers of OS in NSCLC patients. CHAF1B expression had an impact on mortality, as patients with high CHAF1B expression had a significantly poorer OS than those with low CHAF1B expression $[R R=2.44,90 \%$ confidence interval $(\mathrm{CI}) 1.50,3.96]$. We further confirmed the association between $\mathrm{CHAF} 1 \mathrm{~B}$ and $\mathrm{OS}$ in this cohort, thereby demonstrating that $\mathrm{CHAF} 1 \mathrm{~B}$ expression was an independent prognostic factor in NSCLC. The results of the univariate analyses and proportional hazards model are presented in Table IV. To further investigate the clinical value of CHAF1B, the effect of CHAF1B overexpression on NSCLC patient prognosis was explored. The median DFS duration was 17. months for patients with high levels of CHAF1B and 59.70 months for all patients $(\mathrm{P}=0.001)$. However, less than half of the cases in the low-expression group experienced relapse, and thus, the median DFS was not reached. Kaplan-Meier plots were used to analyse the association between CHAF1B expression and OS or DFS in patients (Fig. 2). Highlighting the prognostic value of CHAF1B, patients with high CHAF1B immunoreactivity had poor outcomes, as indicated by the high rates of death and short DFS durations. These results strongly indicated that CHAF1B was associated with NSCLC development and progression; CHAF1B overexpression predicted poor clinical outcomes in NSCLC patients.

CHAFIB promotes NSCLC cell proliferation in vitro. To determine the possible contributions of $\mathrm{CHAF} 1 \mathrm{~B}$ to tumour proliferation, 95-D cells were transfected with sh-CHAF1B or sh-NC plasmids and stably transfected cell lines were established. Four independent shRNA molecules were designed against $\mathrm{CHAF} 1 \mathrm{~B}$, and $\mathrm{CHAF} 1 \mathrm{~B}$ expression was suppressed to varying degrees. The knockdown efficiency of CHAF1B was verified by qRT-PCR and western blotting (Fig. 3A). The 
Table IV. Univariate and multivariate proportional hazard Cox analyses of overall survival.

\begin{tabular}{|c|c|c|c|c|c|c|c|c|c|}
\hline \multirow[b]{2}{*}{ Variables } & \multirow[b]{2}{*}{ Groups } & \multicolumn{5}{|c|}{ Log-rank test } & \multicolumn{3}{|c|}{ Cox proportional hazards model } \\
\hline & & Deaths & Survival & Survival rate & $\chi^{2}$ & P-value & $\hat{\beta}$ & $\mathrm{RR}(90 \% \mathrm{CI})$ & P-value \\
\hline \multirow[t]{2}{*}{ Sex } & Male & 39 & 63 & 61.8 & 0.751 & 0.386 & & & \\
\hline & Female & 16 & 17 & 51.5 & & & & & \\
\hline \multirow{2}{*}{ Pathological type } & Squamous & 24 & 41 & 63.1 & 0.473 & 0.492 & & & \\
\hline & Adenocarcinoma & 31 & 39 & 55.7 & & & & & \\
\hline \multirow[t]{2}{*}{ Histological grade } & III & 34 & 34 & 50.0 & 5.811 & 0.016 & & & \\
\hline & $\mathrm{I} / \mathrm{II}$ & 21 & 46 & 68.7 & & & & & \\
\hline \multirow[t]{2}{*}{ Lymph node metastasis } & No & 21 & 60 & 74.4 & 21.944 & $<0.001$ & & & \\
\hline & Yes & 34 & 19 & 35.8 & & & 0.71 & $2.02(1.13,3.62)$ & 0.046 \\
\hline \multirow[t]{3}{*}{ TNM stage } & I & 9 & 37 & 80.4 & 26.521 & $<0.001$ & & & \\
\hline & II & 22 & 33 & 60.0 & & & 0.37 & $1.45(0.71,2.99)$ & 0.395 \\
\hline & III & 24 & 10 & 29.4 & & & 0.90 & $2.45(1.07,5.61)$ & 0.075 \\
\hline \multirow{2}{*}{ Vascular invasion } & No & 49 & 72 & 59.5 & 0.021 & 0.885 & & & \\
\hline & Yes & 6 & 8 & 57.1 & & & & & \\
\hline \multirow[t]{2}{*}{ Smoking } & No & 22 & 27 & 55.1 & 0.381 & 0.537 & & & \\
\hline & Yes & 33 & 53 & 61.6 & & & & & \\
\hline \multirow[t]{3}{*}{ Tumour size $(\mathrm{cm})$} & $<3$ & 4 & 18 & 81.8 & 8.553 & 0.014 & & & \\
\hline & $\geq 3,<5$ & 27 & 41 & 60.3 & & & & & \\
\hline & $\geq 5$ & 24 & 21 & 46.7 & & & & & \\
\hline \multirow[t]{2}{*}{ CHAF1B } & $<4.83$ & 18 & 53 & 74.6 & 16.716 & $<0.001$ & & & \\
\hline & $\geq 4.83$ & 37 & 27 & 42.2 & & & 0.89 & $2.44(1.50,3.96)$ & 0.003 \\
\hline \multirow[t]{2}{*}{ Age (years) } & $<60$ & 34 & 49 & 59.0 & 0.001 & 0.984 & & & \\
\hline & $\geq 60$ & 21 & 31 & 59.6 & & & & & \\
\hline
\end{tabular}

$\chi^{2}$ indicates log-rank test statistics; RR, response rate; CI, confidence interval; TNM stage, tumor-node-metastasis stage of lung cancer; CHAF1B, chromatin assembly factor 1 subunit B. $\hat{\beta}$, regression coefficient.

most efficient shRNA, which reduced CHAF1B expression by $\sim 70 \%$ was chosen for subsequent experiments. The effects of CHAF1B gene silencing on cell proliferation were examined. The CCK-8 assay results indicated that CHAF1B knockdown significantly inhibited proliferation in $95-\mathrm{D}$ cells relative to that in control cells (Fig. 3B). The suppressive effect on cell growth was confirmed by colony formation assays; compared to the sh-NC 95-D cells, the sh-CHAF1B 95-D cells exhibited reduced colony forming activity (Fig. 3C). Collectively, these results revealed that $\mathrm{CHAF} 1 \mathrm{~B}$ promoted the proliferation of 95-D lung cancer cells in vitro. Furthermore, to investigate the possible mechanism of inhibition of cell proliferation, the effect of CHAF1B on apoptosis and cell cycle distribution in 95-D cells was assessed using flow cytometry. CHAF1B knockdown significantly promoted apoptosis in 95-D cells (Fig. 3D). As demonstrated in Fig. 3E, compared with sh-NC, sh-CHAF1B 95-D cells displayed reduced accumulation in the $\mathrm{S}$ phase and increased accumulation in the $\mathrm{G}_{0} / \mathrm{G}_{1}$ phase. Collectively, these data indicated that CHAF1B knockdown likely inhibited 95-D cell proliferation by arresting cells in the $G_{0} / G_{1}$ phase and inducing cell apoptosis.

CHAF1B knockdown inhibits NSCLC cell growth in vivo. To ascertain the effects of CHAF1B on cell proliferation in vivo, a BALB/c mouse lung neoplasm xenograft model was established using 95-D cells. At 40 days post-implantation, the tumours were significantly smaller in the sh-CHAF1B group than in the sh-NC group (Fig. 4A). Additionally, the tumour weights were $1.58 \pm 0.22$ and $0.21 \pm 0.06 \mathrm{~g}$ in the sh-NC and sh-CHAF1B groups, respectively, which was a significant difference (Fig. 4B). The expression of CHAF1B and Ki-67 in the xenograft tumour tissues was also assessed using IHC (Fig. 4C) and CHAF1B levels were estimated using qRT-PCR (Fig. 4D). The results revealed that CHAF1B and $\mathrm{Ki}-67$ expression was downregulated in the xenograft tumours from the sh-CHAF1B group compared with the xenograft tumours of the sh-NC group. Therefore, CHAF1B promoted tumour growth in nude mice, complementing the results of our functional in vitro studies.

CHAF1B expression is positively correlated with $\mathrm{Ki}-67$ expression and may be used as a relevant proliferation marker. The aforementioned experimental results demonstrated that CHAF1B promoted lung cancer cell proliferation in vivo and in vitro. To confirm that $\mathrm{CHAF} 1 \mathrm{~B}$ may be used as a proliferation index, the relationship between CHAF1B and $\mathrm{Ki}-67$, a classic proliferation marker, was determined. Immunohistochemical staining for Ki-67 (Fig. 5A) was performed on the same paraffin 

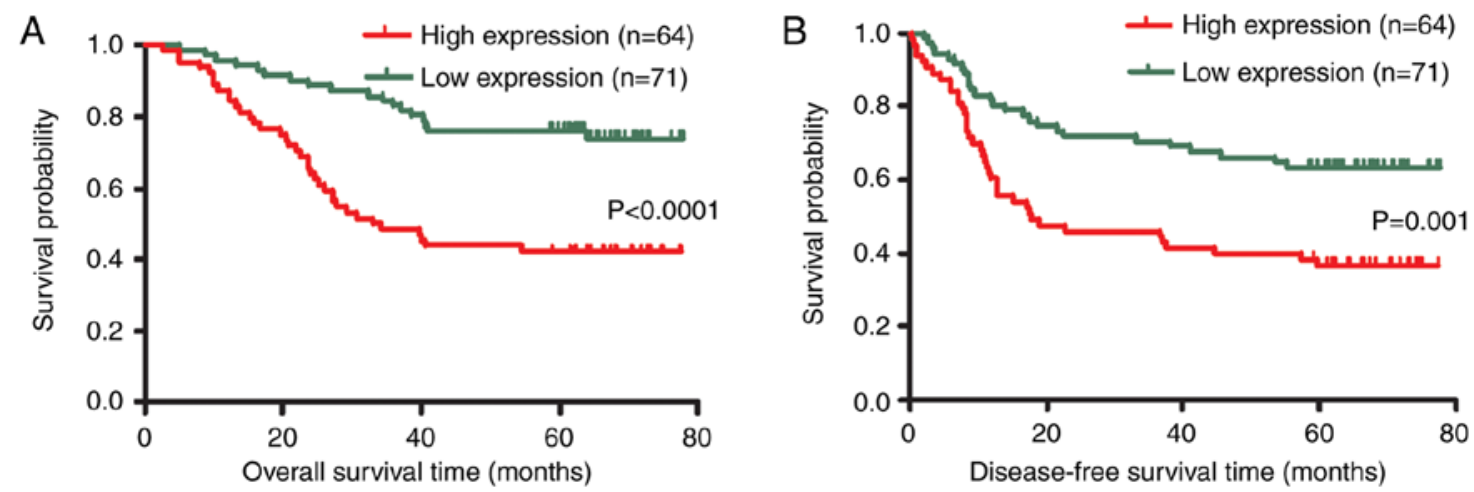

Figure 2. High expression of CHAF1B predicts poor clinical outcomes in NSCLC patients. Kaplan-Meier analyses (log-rank test) of (A) OS and (B) DFS. A cohort of 135 patients with NSCLC were subdivided into low- and high-expression groups based on cut-off scores using time-dependent ROC curves analyses. CHAF1B, chromatin assembly factor 1 subunit B; NSCLC, non-small cell lung cancer; OS, overall survival; DFS, disease-free survival; ROC, receiver operating characteristic.

A
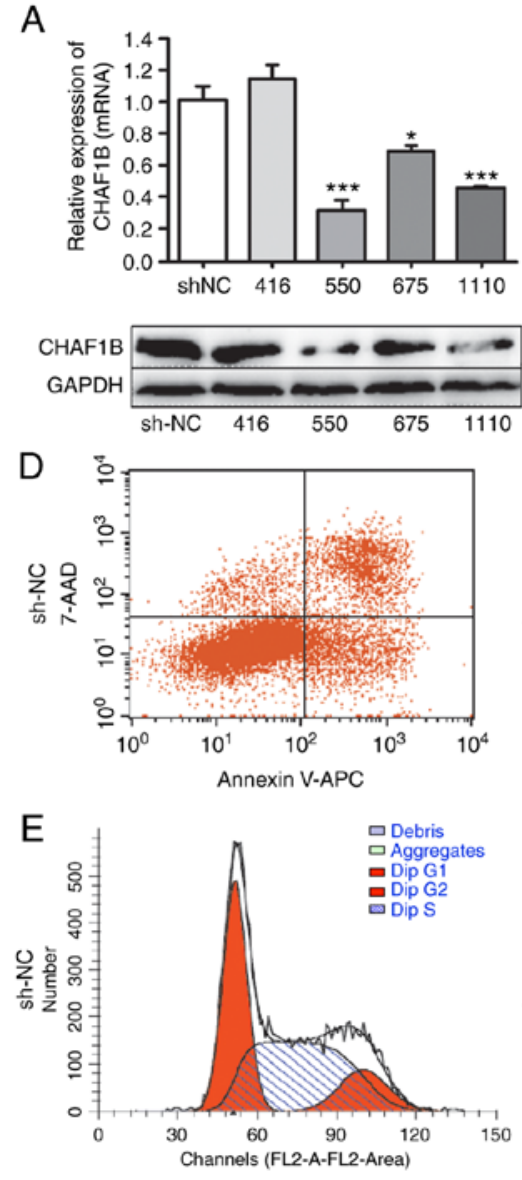
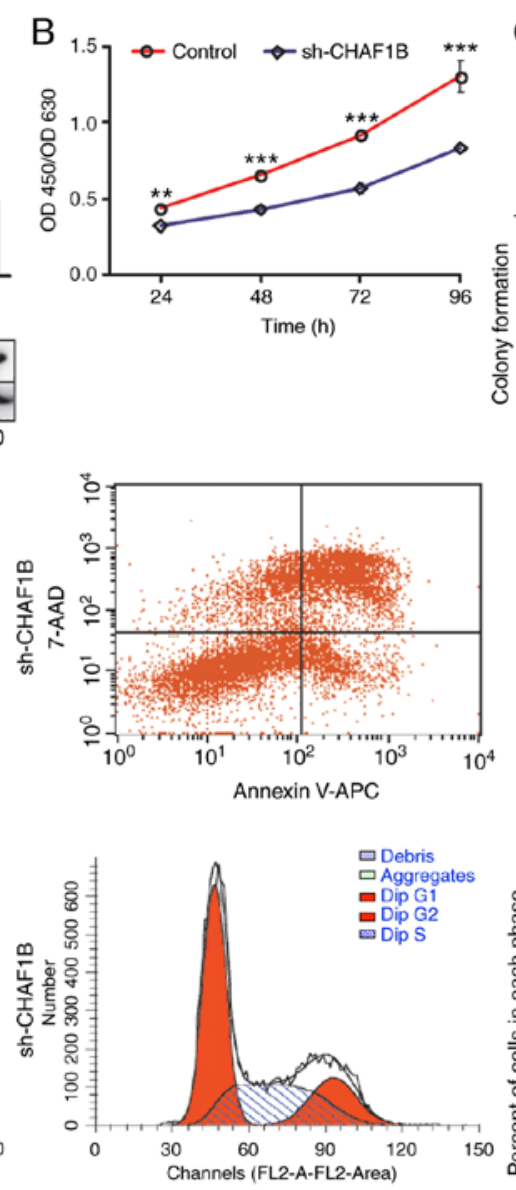
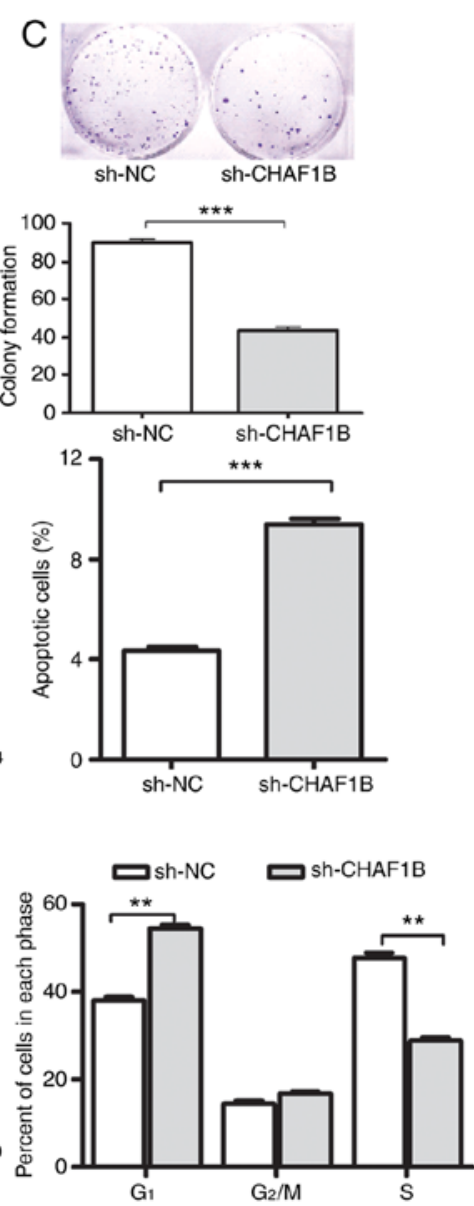

Figure 3. CHAF1B knockdown inhibits the growth of 95-D cell-derived tumours in vitro. (A) CHAF1B mRNA and protein levels were assessed by qRT-PCR and western blotting, respectively, in 95-D cells transfected with sh-NC plasmid or one of the 4 different sh-CHAF1B sequences (CHAF1B-HOMO-416, CHAF1B-HOMO-550, CHAF1B-HOMO-675, CHAF1B-HOMO-1110), with quantification relative to $\beta$-actin. Cell proliferation was assessed by (B) CCK-8 and (C) colony formation assays in 95-D cells transfected with sh-NC or sh-CHAF1B plasmids. The data are presented as the mean \pm SD. (D) Apoptosis was analysed by flow cytometry, and apoptotic cells were quantitated. (E) Cell cycle distribution was analysed by flow cytometry. The data are presented as the mean \pm SD from 3 independent experiments. ${ }^{*} \mathrm{P}<0.05 ;{ }^{* *} \mathrm{P}<0.01 ;{ }^{* * *} \mathrm{P}<0.001$. CHAF1B, chromatin assembly factor 1 subunit $\mathrm{B}$; CCK-8, Cell Counting Kit-8; $\mathrm{SD}$, standard deviation.

sections of CHAF1B and a strong positive correlation was observed between $\mathrm{CHAF} 1 \mathrm{~B}$ and $\mathrm{Ki}-67$ expression $(\mathrm{r}=0.858$, $\mathrm{P}<0.001)$, demonstrating that $\mathrm{CHAF} 1 \mathrm{~B}$ was an indicator of cell proliferation (Fig. 5B).
CHAF1B silencing reduces the expression of apoptosisrelated proteins. To obtain insights into the mechanism, the expression of p53 and intrinsic apoptosis-related proteins, such as BAK, Bcl-2 and caspase-3, was assessed. Compared 
A

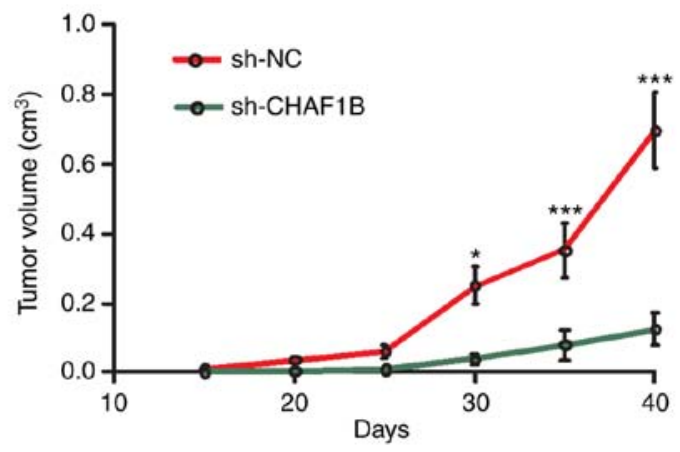

C
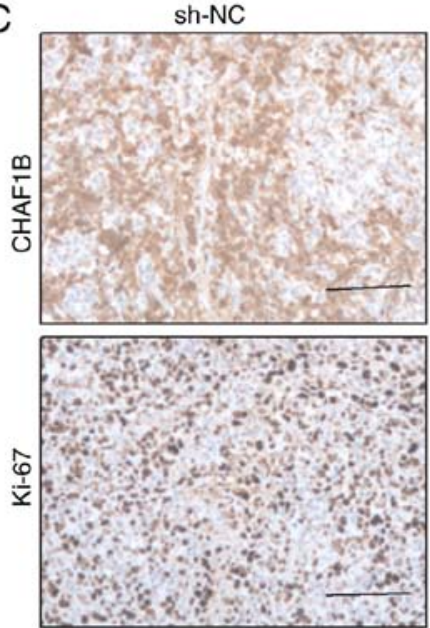

sh-CHAF1B

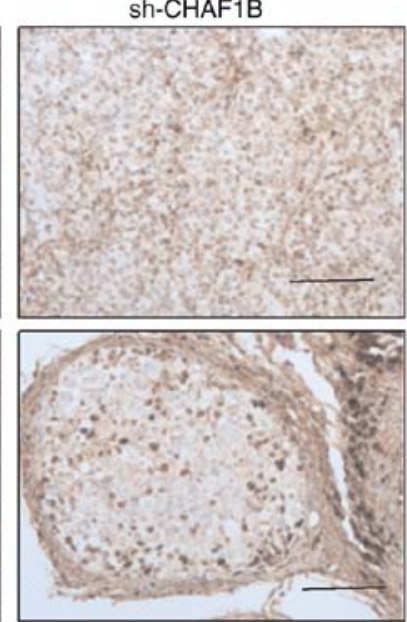

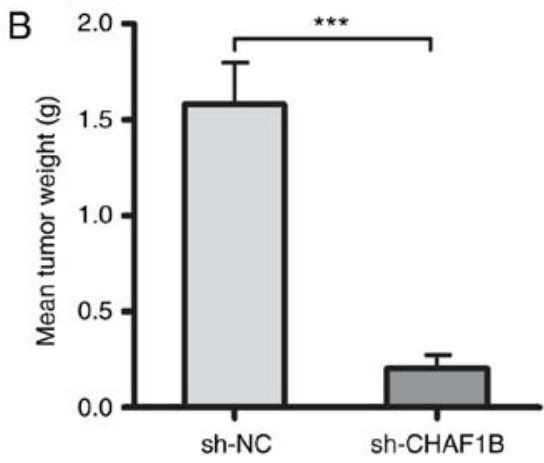

D

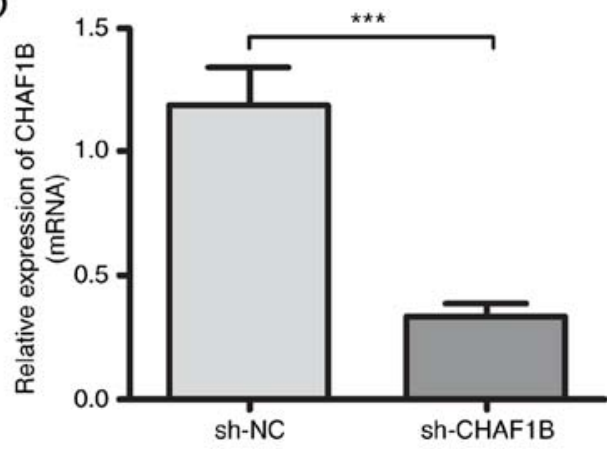

Figure 4. CHAF1B knockdown inhibits the growth of xenograft tumours in vivo. (A) The length and width of xenograft tumours were assessed every 5 days, and tumour volumes were calculated and indicated. Error bars indicate the SEM for each group of 6 mice. (B) At the end of the experimental period, tumours were dissected, and tumour weight was asssessed as displayed in the image. (C) Immunohistochemical analysis of CHAF1B and Ki-67 expression in xenograft tumours derived from cells transfected with sh-CHAF1B or sh-NC (scale bars, $100 \mu \mathrm{m}$ ). (D) CHAF1B mRNA expression levels of xenograft tumours. Actin expression was assessed as a control. The data represent the mean \pm SD. One-way ANOVA or Student's t-test was used to calculate $\mathrm{P}$-values. $\mathrm{n}=6$. ${ }^{*} \mathrm{P}<0.05$; ${ }^{* * * *} \mathrm{P}<0.001$. CHAF1B, chromatin assembly factor 1 subunit B; SEM, scanning electron microscopy; SD, standard deviation; ANOVA, analysis of variance.

A
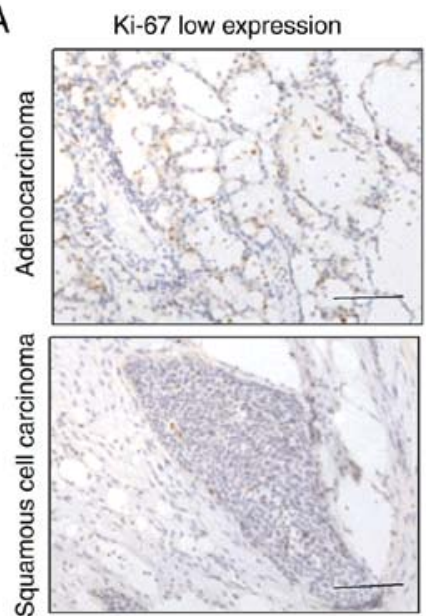

Ki-67 high expression
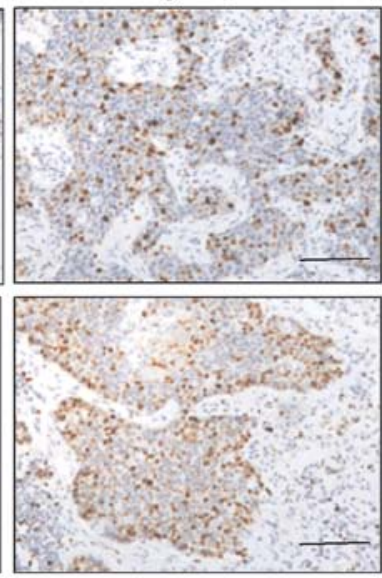

B

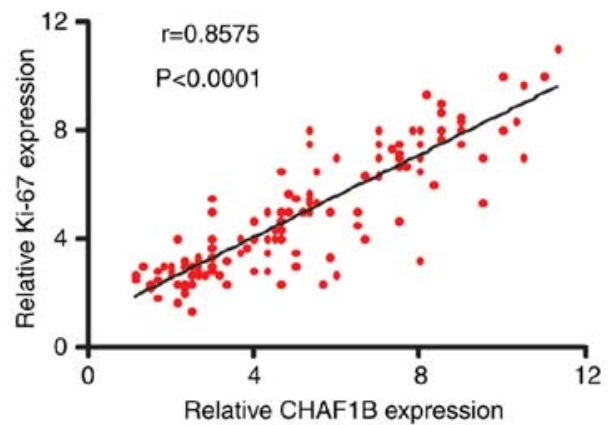

Figure 5. CHAF1B expression is positively correlated with Ki-67 expression. (A) Immunohistochemical staining for Ki-67 in NSCLC, corresponding to the same field of view as for CHAF1B (scale bars, $100 \mu \mathrm{m}$ ). (B) Spearman's correlation between CHAF1B and Ki-67 (r=0.8575, P<0.0001). CHAF1B, chromatin assembly factor 1 subunit B; NSCLC, non-small cell lung cancer.

with cells transfected with sh-NC, p53 expression was upregulated in 95-D cells transfected with sh-CHAF1B (Fig. 6A). Additionally, a significant upregulation of the pro-apoptotic protein BAK was observed in sh-CHAF1B 95-D cells (Fig. 6B). In contrast, the expression of the anti-apoptotic protein
Bcl-2 was significantly downregulated when $\mathrm{CHAF} 1 \mathrm{~B}$ was silenced in 95-D cells, resulting in an increased BAK/Bcl-2 ratio (Fig. 6C). In addition, the levels of caspase-3 were 4.95-fold higher in the sh-CHAF1B cells than in the sh-NC cells (Fig. 6D). Consistent with the change in mRNA levels, 
A

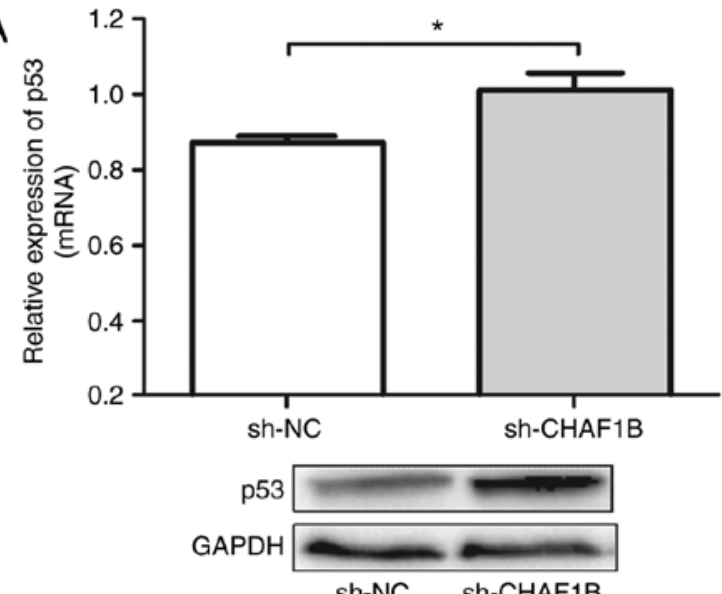

C

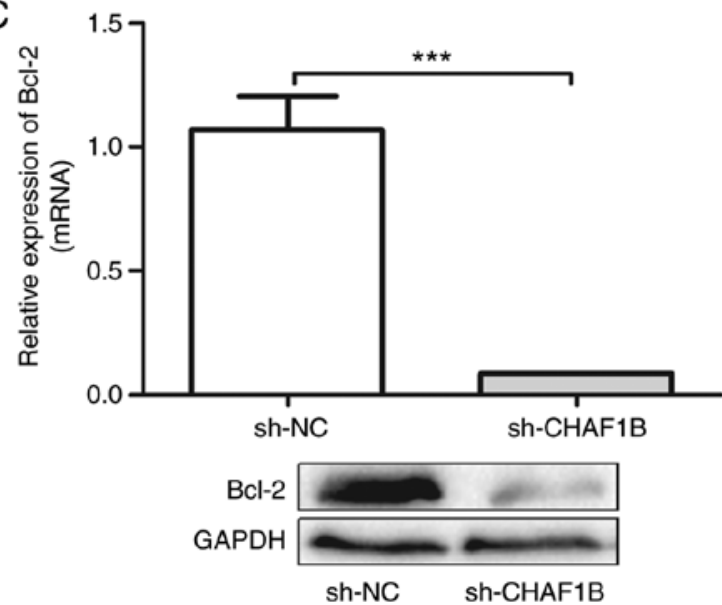

B

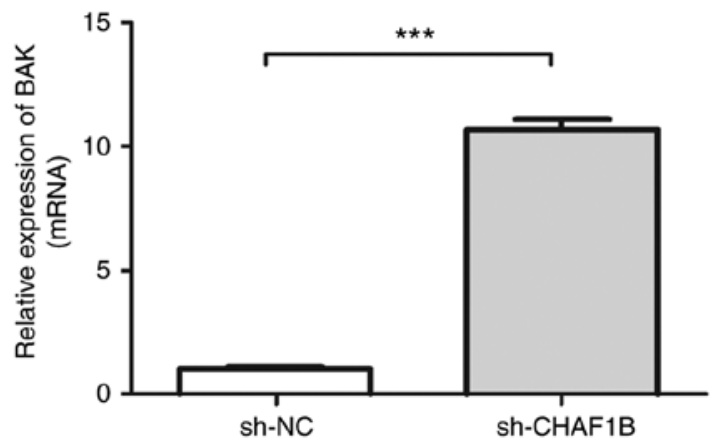

BAK

GAPDH

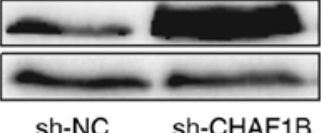

D

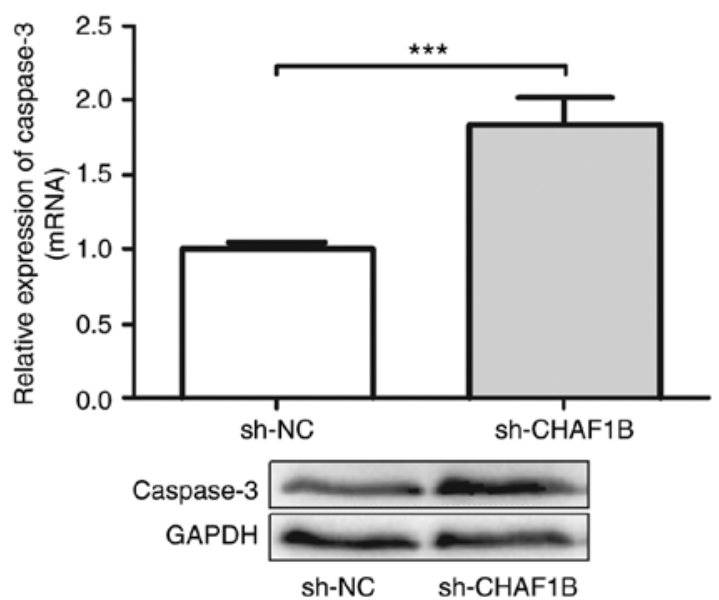

Figure 6. Effect of sh-CHAF1B on the expression of apoptotic markers in 95-D cells. The mRNA and protein levels of (A) p53, (B) BAK, (C) Bcl-2, and (D) caspase-3 were analysed by qRT-PCR and western blotting, respectively, in 95-D cells transfected with sh-CHAF1B or sh-NC. Actin expression was assessed as a control. Data represent the mean \pm SD from 3 independent experiments. ${ }^{*} \mathrm{P}<0.05 ;{ }^{* * *} \mathrm{P}<0.001$. $\mathrm{CHAF} 1 \mathrm{~B}$, chromatin assembly factor 1 subunit $\mathrm{B}$; SD, standard deviation.

the western blot results confirmed the change in p53, BAK, Bcl-2 and caspase- 3 protein levels. Based on these results, the induction of cell apoptosis and inhibition of tumour growth by CHAF1B knockdown was dependent on the p53-induced apoptosis pathway.

\section{Discussion}

In the present study, the expression levels of CHAF1B in NSCLC tissue samples were examined using IHC and qRT-PCR and it was revealed that CHAF1B expression was significantly upregulated in lung cancer tissues but weakly or not expressed in normal lung tissues. Moreover, patients with higher CHAF1B protein expression levels had higher TNM stages, larger tumours, and higher pathological grades, as well as higher mortality and shorter DFS. These results indicated that CHAF1B plays an important role as a tumour-promoting gene in NSCLC development and progression. Although $\mathrm{CHAF} 1 \mathrm{~B}$ is overexpressed in many human malignancies and is associated with a poor prognosis (9-16), its biological function in oncogenesis remains unclear. In the present study, 3 human NSCLC cell lines, namely, 95-D, A549 and NCI-H292, were selected to evaluate $\mathrm{CHAF} 1 \mathrm{~B}$ expression. It was revealed that the 95-D cell line expressed markedly higher levels of
CHAF1B than normal bronchial epithelial cells. This finding may be related to the fact that $95-\mathrm{D}$ originated from a highly metastatic human pulmonary adenocarcinoma cell line with characteristics such as rapid proliferation, strong invasion, and high incidence of metastasis. Thus, 95-D cells stably transfected with sh-CHAF1B were established. CHAF1B knockdown in 95-D cells decreased growth, reduced colony formation, caused cell cycle arrest, and increased apoptosis, indicating that $\mathrm{CHAF} 1 \mathrm{~B}$ promoted proliferation. In the future, we will continue to collect fresh tissues samples from NSCLC patients and add the cell lines NCI-H1975, SK-MES-1 and NCI-H460 to strengthen our findings. In vivo studies also confirmed the role of $\mathrm{CHAF} 1 \mathrm{~B}$ in promoting proliferation. Mechanistic studies demonstrated that CHAF1B knockdown activated p53, which led to changes in the expression of BAK, Bcl-2 and caspase-3 in 95-D cells. The aforementioned results indicated that CHAF1B knockdown promoted apoptosis by activating the p53-dependent apoptotic signalling pathway.

Uncontrolled proliferation is considered one of the most basic biological behaviours in cancer (8). There are two ways to evaluate cell proliferation: By detecting cells that are in one of the key stages of cell proliferation, such as mitosis (mitotic index) or replication (S phase fraction), and by detecting proliferation-related proteins (19). In the present 
study, we used these two methods to assess proliferation. Cell cycle distribution was assessed using flow cytometry. The percentage of sh-CHAF1B-transfected cells at the $\mathrm{G}_{1}$ phase was significantly increased, while the fraction of cells in the $\mathrm{S}$ phase was predominantly decreased. The direct relationship between CAF-1 activity and DNA replication highlights the pivotal role of CAF-1 in the S phase. Proliferating HeLa cells transfected with small interfering RNAs (siRNAs) against CHAF1B exhibited high levels of cell death and did not appear quiescent, likely due to the inability to properly replicate DNA. However, the loss of functionality in nucleosome assembly could be restored by adding recombinant $\mathrm{CHAF} 1 \mathrm{~B}$, indicating that $\mathrm{CHAF} 1 \mathrm{~B}$ is an essential factor for proliferating cells in the $\mathrm{S}$ phase (20). Moreover, Polo et al compared chromatin assembly factor 1 subunit A (CHAF1A) and CHAF1B expression levels in quiescent and asynchronously proliferating cells and determined that $\mathrm{CHAF} 1 \mathrm{~B}$ was markedly downregulated in quiescent cells. The results of their study revealed that $\mathrm{CHAF} 1 \mathrm{~B}$ is a powerful marker for differentiating between proliferating and resting cells (13). Furthermore, the correlation between $\mathrm{CHAF} 1 \mathrm{~B}$ and $\mathrm{Ki}-67$, a marker of cellular proliferation $(21,22)$, was also analysed, and the expression levels of these proteins were highly correlated. These studies directly and indirectly demonstrated that $\mathrm{CHAF} 1 \mathrm{~B}$ is required for DNA replication-linked chromatin assembly and is an important factor for cell proliferation.

In the present study, the relationship between CHAF1B expression and clinicopathological variables was evaluated. Notably, it was revealed that CHAF1B was significantly associated with the male sex, smoking and squamous cell carcinoma. Moreover, high $\mathrm{CHAF} 1 \mathrm{~B}$ protein expression was frequently observed in squamous cell carcinoma, and two cases of extremely high expression of CHAF1B mRNA were also observed in squamous cell carcinoma. There are also some studies of high CHAF1B expression in oral squamous cell carcinoma (OSCC), laryngeal squamous cell carcinoma (LSCC), skin squamous cell carcinoma (SSCC) (23) and squamous cell carcinoma of the tongue (12). Although these studies described the phenomenon, they did not determine why CHAF1B is highly expressed in squamous cell carcinoma. Nicotine has been revealed to promote tumour cell proliferation (24), and CAF-1 activity to be closely related to DNA replication and cell proliferation. The association among nicotine, CAF-1 and cell proliferation may explain why CHAF1B was revealed to be associated with the male sex, smoking, and squamous cell carcinoma. Therefore, CHAF1B may be a potential oncogene in lung squamous cell carcinoma. However, this hypothesis requires validation in well-designed investigations of cellular function and more patient cohorts. This research direction will be pursued in the future.

Few studies have reported on the relationship between CHAF1B and p-53. Barbieri et al revealed that RAS as well as AKT, BMI and ALK signalling pathways are strongly inhibited after CHAF1A knockdown in neuroblastoma tumourigenesis (25). However, the AKT, p53 and TOR pathways have been implicated in communication and coordination to regulate cell growth, proliferation and apoptosis (26). Since p53 primarily functions as a transcription factor, it plays an important role in inducing apoptosis and cell cycle arrest. p53 activates the intrinsic apoptotic pathway (27), which is dominated by the
Bcl-2 family of proteins $(28,29)$. p53 forms a complex with its effectorBAK, which is a pro-apoptotic mitochondrialmembrane protein, and cytochrome $c$ is released from the mitochondria, resulting in cell apoptosis (30). Moreover, p53 interacts with Bcl-2 to form a complex that antagonizes the anti-apoptotic functions of $\mathrm{Bcl}-2$ and induces mitochondrial permeability via cytochrome $c$ release. However, tumour-derived mutant p53 does not bind to Bcl-2 to form a complex and thus cannot induce outer mitochondrial membrane permeabilization and cytochrome $c$ release, indicating the physiological importance of p53-induced mitochondrial apoptosis (31).

In addition, p53 induces cell cycle arrest. p53 can induce $\mathrm{G}_{1}$ arrest by activating the transcription of cyclin-dependent kinase inhibitor p21 (32) and can also inhibit the activity of the cyclin-dependent kinase $\mathrm{Cdc} 2$, contributing to $\mathrm{G}_{2}$ arrest (33).

Collectively, these data indicated that p53 induces endogenous apoptosis by regulating the Bcl-2 family of proteins. It was revealed that $\mathrm{CHAF} 1 \mathrm{~B}$ upregulated the expression of p53, BAK and caspase-3 and downregulated the expression of anti-apoptotic protein Bcl-2 in 95-D cells. Collectively, our findings indicated that knockdown of CHAF1B inhibited cell proliferation and induced apoptosis by activating the p53-dependent apoptotic signalling pathway (BAK/Bcl-2/caspase-3) in 95-D cells. Concurrently, our findings indicated that $\mathrm{CHAF} 1 \mathrm{~B}$ silencing can block cell cycle progression. However, the exact molecular mechanism requires further investigation.

In the present study, it was demonstrated that CHAF1B overexpression is associated with poor clinical outcomes of NSCLC and confirmed the proliferation-promoting effect of $\mathrm{CHAF} 1 \mathrm{~B}$, thereby indicating its potential as a therapeutic molecular target to counter NSCLC progression.

\section{Acknowledgements}

The authors would like to thank Sutang Guo and Feng Li for their technological support and valuable advice.

\section{Funding}

No funding was received.

\section{Availability of data and materials}

All data generated or analysed during the present study are included in this published article.

\section{Authors' contributions}

YD, JL and HZ conceived and designed the study. YD, MH, TL, SL and XL participated in the implementation of the study and interpreted the data. YD, TL and SL drafted the manuscript and revised the version. All authors read and approved the final manuscript and agree to be accountable for all aspects of the work in ensuring that questions related to the accuracy or integrity of any part of the work are appropriately investigated and resolved.

\section{Ethics approval and consent to participate}

The aspects of the present study involving human participants were approved by the Shanxi Provincial Cancer Hospital Ethics 
Committee, and the study was conducted in accordance with the Declaration of Helsinki. The animal studies were approved by the Shanxi Institute of Tumor Research, and all procedures were performed in accordance with the relevant guidelines and regulations. All participants in the study provided written informed consent.

\section{Patient consent for publication}

Not applicable.

\section{Competing interests}

All authors declare that they have no competing interests.

\section{References}

1. Siegel RL, Miller KD and Jemal A: Cancer statistics, 2017. CA Cancer J Clin 67: 7-30, 2017.

2. Chen W, Zheng R, Baade PD, Zhang S, Zeng H, Bray F, Jemal A, Yu XQ and He J: Cancer statistics in China, 2015. CA Cancer J Clin 66: 115-132, 2016.

3. Chan BA and Hughes BG: Targeted therapy for non-small cell lung cancer: Current standards and the promise of the future. Transl Lung Cancer Res 4: 36-54, 2015.

4. Chen Z, Fillmore CM, Hammerman PS, Kim CF and Wong K-K: Non-small-cell lung cancers: A heterogeneous set of diseases. Nature Rev Cancer 14: 535, 2014.

5. Smith S and Stillman B: Purification and characterization of CAF-I, a human cell factor required for chromatin assembly during DNA replication in vitro. Cell 58: 15-25, 1989.

6. Verreault A, Kaufman PD, Kobayashi R and Stillman B: Nucleosome assembly by a complex of CAF-1 and acetylated histones H3/H4. Cell 87: 95-104, 1996.

7. Kaufman PD, Kobayashi R, Kessler N and Stillman B: The p150 and p60 subunits of chromatin assembly factor I: A molecular link between newly synthesized histones and DNA replication. Cell 81: 1105-1114, 1995.

8. Evan GI and Vousden KH: Proliferation, cell cycle and apoptosis in cancer. Nature 411: 342-348, 2001.

9. Tayrac MD, Saikali S, Aubry M, Bellaud P, Boniface R, Quillien V and Mosser J: Prognostic significance of EDN/RB, HJURP, p60/CAF-1 and PDLI4, four new markers in high-grade gliomas. PLoS One 8: e73332, 2013.

10. Tayrac MD, Aubry M, Saïkali S, Etcheverry A, Surbled C, Guénot F, Galibert MD, Hamlat A, Lesimple T, Quillien V, et al: A 4-Gene signature associated with clinical outcome in high-grade gliomas. Clin Cancer Res 17: 317-327, 2011.

11. Staibano S, Mascolo M, Mancini FP, Kisslinger A, Salvatore G, Di Benedetto M, Chieffi P, Altieri V, Prezioso D, Ilardi G, et al: Overexpression of chromatin assembly factor-1 (CAF-1) p60 is predictive of adverse behaviour of prostatic cancer. Histopathology 54: 580-589, 2009.

12. Staibano S, Mignogna C, Lo Muzio L, Mascolo M, Salvatore G, Di Benedetto M, Califano L, Rubini C and De Rosa G: Chromatin assembly factor-1 (CAF-1)-mediated regulation of cell proliferation and DNA repair: A link with the biological behaviour of squamous cell carcinoma of the tongue? Histopathology 50: 911-919, 2007.

13. Polo SE, Theocharis SE, Klijanienko J, Savignoni A, Asselain B, Vielh P and Almouzni G: Chromatin assembly factor-1, a marker of clinical value to distinguish quiescent from proliferating cells. Cancer Res 64: 2371-2381, 2004.
14. Staibano S, Mascolo M, Rocco A, Lo Muzio L, Ilardi G, Siano M, Pannone G, Vecchione ML, Nugnes L, Califano L, et al: The proliferation marker chromatin assembly factor-1 is of clinical value in predicting the biological behaviour of salivary gland tumours. Oncol Rep 25: 13-22, 2011.

15. Polo SE, Theocharis SE, Grandin L, Gambotti L, Antoni G, Savignoni A, Asselain B, Patsouris E and Almouzni G: Clinical significance and prognostic value of chromatin assembly factor-1 overexpression in human solid tumours. Histopathology 57: 716-724, 2010.

16. Mascolo M, Vecchione ML, Ilardi G, Scalvenzi M, Molea G, Di Benedetto M, Nugnes L, Siano M, De Rosa G and Staibano S: Overexpression of chromatin assembly Factor-1/p60 helps to predict the prognosis of melanoma patients. BMC Cancer 10: 63, 2010.

17. Livak KJ and Schmittgen TD: Analysis of relative gene expression data using real-time quantitative PCR and the $2^{-\Delta \Delta C_{\mathrm{T}}}$ method. Methods 25: 402-408, 2001.

18. Naito S, von Eschenbach AC, Giavazzi R and Fidler IJ: Growth and metastasis of tumour cells isolated from a human renal cell carcinoma implanted into different organs of nude mice. Cancer Res 46: 4109-4115, 1986.

19. Hall PA and Levison DA: Review: Assessment of cell proliferation in histological material. J Clin Pathol 43: 184-192, 1990.

20. Nabatiyan A and Krude T: Silencing of chromatin assembly factor 1 in human cells leads to cell death and loss of chromatin assembly during DNA synthesis. Mol Cell Biol 24: 2853-2862, 2004.

21. Gerdes J, Schwab U, Lemke H and Stein H: Production of a mouse monoclonal antibody reactive with a human nuclear antigen associated with cell proliferation. Int J Cancer 31: 13-20, 1983.

22. Brown DC and Gatter KC: Monoclonal antibody Ki-67: Its use in histopathology. Histopathology 17: 489-503, 1990.

23. Mascolo M, Ilardi G, Merolla F, Russo D, Vecchione ML, de Rosa G and Staibano S: Tissue microarray-Based evaluation of chromatin assembly factor-1 (CAF-1)/p60 as tumour prognostic marker. Int J Mol Sci 13: 11044-11062, 2012.

24. Schaal C and Chellappan SP: Nicotine-mediated cell proliferation and tumor progression in smoking-related cancers. Mol Cancer Res 12: 14-23, 2014.

25. Barbieri E, De Preter K, Capasso M, Chen Z, Hsu DM, Tonini GP, Lefever S, Hicks J, Versteeg R, Pession A, et al: Histone chaperone CHAF1A inhibits differentiation and promotes aggressive neuroblastoma. Cancer Res 74: 765-774, 2014.

26. Levine AJ, Feng Z, Mak TW, You H and Jin S: Coordination and communication between the p53 and IGF-1-AKT-TOR signal transduction pathways. Genes Dev 20: 267-275, 2006.

27. Marchenko ND, Zaika A and Moll UM: Death signal-induced localization of p53 protein to mitochondria. A potential role in apoptotic signaling. J Biol Chem 275: 16202-16212, 2000.

28. Kuwana T, Mackey MR, Perkins G, Ellisman MH, Latterich M, Schneiter R, Green DR and Newmeyer DD: Bid, bax, and lipids cooperate to form supramolecular openings in the outer mitochondrial membrane. Cell 111: 331-342, 2002.

29. Cory S and Adams JM: The Bcl2 family: Regulators of the cellular life-or-death switch. Nat Rev Cancer 2: 647-656, 2002.

30. Leu J, Dumont P, Hafey M, Murphy ME and George DL: Mitochondrial p53 activates Bak and causes disruption of a Bak-Mcll complex. Nat Cell Biol 6: 443-450, 2004.

31. Tomita Y, Marchenko N, Erster S, Nemajerova A, Dehner A, Klein C, Pan H, Kessler H, Pancoska P and Moll UM: WT p53, but not tumor-derived mutants, bind to Bcl2 via the DNA binding domain and induce mitochondrial permeabilization. J Biol Chem 281: 8600-8606, 2006.

32. Giono LE and Manfredi JJ: The p53 tumor suppressor participates in multiple cell cycle checkpoints. J Cell Physiol 209: 13-20, 2006.

33. Nurse P: Universal control mechanism regulating onset of M-phase. Nature 344: 503-508, 1990. 